\title{
Decision Support System in Determining Outstanding Teachers in Tutoring Institution Uses The Simple Additive Weighting method. (Case Study : Tutoring Dunia Sausan Kudus)
}

\author{
Ning Rahayu Lestari ${ }^{1}$, Mukhamad Nurkamid ${ }^{2}$ \\ ${ }^{1}$ Program Studi Teknik Informatika, Fakultas Teknik, Universitas Muria Kudus \\ Jl. Gondangmanis Bae Kudus Jawa Tengah, e-mail: ningrahayulestari637@gmail.com \\ ${ }_{2}^{2}$ Program Studi Teknik Informatika, Fakultas Teknik, Universitas Muria Kudus \\ Jl. Gondangmanis Bae Kudus Jawa Tengah, e-mail: muhammad.nurkamid@umk.ac.id
}

\section{ARTICLE INFO}

Article history:

Received : 22 May 2019

Received in revised form : 01 July 2019

Accepted : 25 july 2019

Available online : 31 July 2019

\begin{abstract}
Tutoring is helping students to get good adjustments in learning situations, so that each student can learn efficiently according to his abilities and achieve optimal development. In tutoring need to need outstanding teachers to produce high achieving students. With the existence of a decision support system, the admin or head of tutoring can determine the instructors who have achievements, and can manage teaching data, employee data safely and efficiently. In this decision support system uses the SAW (Simple Additive Weighting) method. This system was developed using the PHP programming language and MySQL database. The final results of this study found that the SAW (Simple Additive Weighting) method was able to overcome the problems in determining teachers who excel, and can manage teaching data, employee data safely and efficiently.
\end{abstract}

Keywords: Decision Support System, Tutoring, Dunia Sausan Kudus

\section{Pendahuluan}

Pada saat ini pemanfaatan ilmu pengetahuan dan teknologi berkembang dengan sangat cepat sekali dan menghasilkan inovasi - inovasi baru yang harus diimbangi dengan kemampuan beradaptasi dengan teknologi jaman sekarang. Berdasarkan hasil survey tahun 2007 yang 
diadakan oleh Direktorat Pembinaan Kursus dan Kelembagaan Ditjen Pendidikan Nonformal dan Informal Kemendiknas terdapat 13.446 lembaga kursus yang tersebar di seluruh Indonesia, 11.207 lembaga $(83,35 \%)$ telah memiliki izin operasi. Sisanya 10,20\% lembaga sedang dalam proses mengurus izin dan 6,54\% lembaga belum memiliki izin. Dari data jumlah lembaga kursus yang memiliki izin tersebut dapat diketahui bahwa jumlah Bimbingan Belajar adalah sebesar 10,13\%. Sedangkan jumlah Bimbingan Belajar seluruhnya diperkirakan sebanyak 1.362 lembaga, yaitu 1.135 ada NILEK dan 227 lembaga yang belum memiliki atau sedang mengurus izin (Bank Indonesia, 2010).

Dalam lembaga bimbingan belajar perlu kita ketahui dalam menentukan guru pengajar yang baik dan berprestasi, supaya kita bisa mengetahui manakah pengajar yang bisa benar - benar mendidik siswa dengan baik. Maka dari itu dalam menentukan pengajar yang berprestasi bisa menggunakan sistem pendukung keputusan dengan metode SAW (Simple Additive Weighting). Salah satu bentuknya adalah Sistem Pendukung Keputusan (SPK). Sistem ini adalah suatu sistem berbasis komputer yang menghasilkan berbagai alternatif keputusan untuk membantu dalam menangani berbagai permasalahan yang semi terstruktur ataupun tidak terstruktur dengan menggunakan data dan model analisa. Tujuan penelitian ini adalah membangun sebuah aplikasi sistem penunjang keputusan yang dapat digunakan oleh pihak bimbel dunia sausan untuk manganalisa seberapa besar pengaruh kinerja pengajar terhadap optimalisasi pengembangan pendidikan.

\section{Metode Penelitian}

Metode penelitian adalah suatu cara atau prosedur yang digunakan untuk mengumpulkan, mengolah dan menganalisa data pada menentukan pengajar berprestasi.

1. Tahap Analisis Kebutuhan

Terdiri dari pengumpulan data pengajar pada bimbingan belajar di Dunia Sausan Kudus, baik dari internet maupun wawancara dengan mendatangi bimbingan belajar Dunia Sausan Kudus yang akan dijadikan sampel.

2. Tahap Perancangan

Pada tahap ini desain sistem mulai dibangun meliputi data flow diagram (DFD), entity relationship diagram (ERD), basis data, struktur tabel, dan antar muka (interface). Desain ini dimulai sebelum tahap implementasi.

3. Tahap Implementasi

Tahap dimana penulisan kode program mulai dilakukan. Tahap implementasi dimulai setelah tahap desain sistem sudah terselesaikan.

4. Tahap Testing

Tahap dimana dilakukannya testing atau pengujian terhadap sistem yang dibangun.

Setelah semua fitur dalam sistem berjalan sebagaimana fungsinya, selanjutnya akan dipublish secara online agar dapat digunakan oleh semua pengguna. Metode pengujian yang digunakan menggunaan metode blackbox.

5. Tahap Pemeliharaan (maintenance)

Tahap ini merupakan tahap terakhir dari metode waterfall, dimana sistem yang sudah dijalankan dan di-publish akan dilakukan pemeliharaan. Pada tahap ini juga dilakukan perbaikan kesalahan-kesalahan yang sebelumnya tidak ditemukan.

\section{Metode Pengembangan Sistem}

Perancangan sistem pendukung keputusan mengunakan metode waterfall. Teknik ini dipilih karena pengembangan sistem yang dilakukan lebih terstruktur dengan adanya tahap-tahap yang dilakukan secara terurut dan setiap tahap harus diselesaikan terlebih dahulu untuk menghindari terjadinya pengulangan dalam tahapan sehingga pengembangan sistem yang dilakukan dapat memperoleh hasil yang diinginkan. 


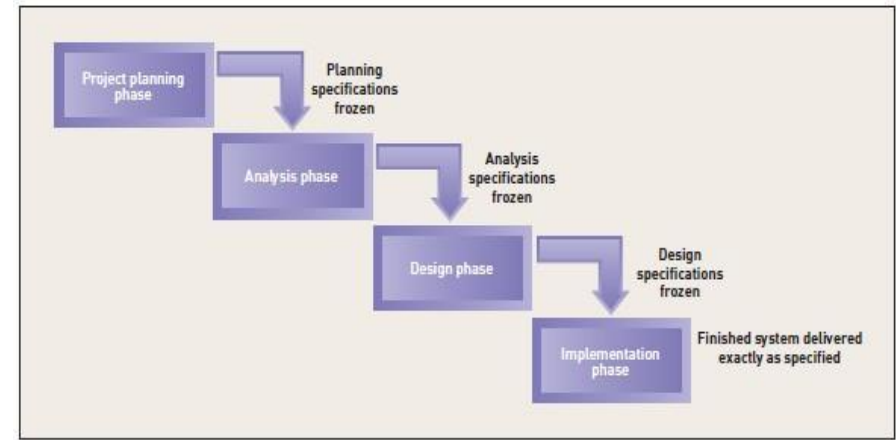

Gambar 1. Metode Waterfall

\section{Metode Yang Digunakan}

A. Simple Additive Weighting

Metode Simple Additive Weighting (SAW) merupakan salah satu metode untuk penyelesaian masalah Multi Attribute Decision Making. Metode SAW sering dikenal dengan istilah metode penjumlahan terbobot. Konsep dasar metode SAW adalah mencari penjumlahan terbobot dari rating kinerja pada setiap alternatif pada semua atribut. Metode SAW dapat membantu dalam pengambilan keputusan suatu kasus, akan tetapi perhitungan dengan menggunakan metode SAW ini hanya yang menghasilkan nilai terbesar yang akan terpilih sebagai alternatif yang terbaik. Perhitungan akan sesuai dengan metode ini apabila alternatif yang terpilih memenuhi kriteria yang telah ditentukan. Metode SAW ini lebih efisien karena waktu yang dibutuhkan dalam perhitungan lebih singkat. Metode SAW membutuhkan proses normalisasi matriks keputusan $(X)$ ke suatu skala yang dapat diperbandingkan dengan semua rating alternatif yang ada.

Berikut adalah langkah penyelesaian metode SAW :

1) Menentukan kriteria-kriteria yang akan dijadikan acuan dalam pengambilan keputusan.

2) Menentukan rating kecocokan setiap alternatif pada setiap kriteria.

3) Membuat matriks keputusan berdasarkan kriteria $(C l)$, kemudian melakukan normalisasi matriks berdasarkan persamaan yang disesuaikan dengan jenis atribut (atribut keuntungan ataupun atribut biaya) sehingga diperoleh matriks ternormalisasi $R$.

4) Hasil akhir diperoleh dari proses perankingan yaitu penjumlahan dari perkalian matriksternormalisasi $R$ dengan vektor bobot sehingga diperoleh nilai terbesar yang dipilih sebagai alternatif terbaik

5) (Al) sebagai solusi. Formula untuk melakukan normalisasi tersebut adalah:

$$
r_{i j}\left\{\begin{array}{lll}
\frac{x_{i j}}{\operatorname{Max}_{i} x_{i j}} & \longrightarrow & \text { Jika j adalah atribut keuntungan (benefit) } \\
\frac{\operatorname{Min}_{i} x_{i j}}{x_{i j}} & \longrightarrow & \text { Jika j adalah atribut biaya (cost) }
\end{array}\right.
$$

Keterangan:

rij $=$ rating kinerja ternormalisasi

$\max x i j=$ nilai maksimum dari setiap baris dan kolom

min $x i j=$ nilai minimum dari setiap baris dan kolom

$\mathrm{xij}=$ baris dan kolom dari matriks

Dengan rij adalah rating kinerja ternormalisasi dari alternatif $A i$ pada atribut $C j$;

$i=1,2, \ldots, m$ dan $j=1,2, \ldots, n$. Nilai preferensi untuk setiap alternatif $(V I)$

$v_{i j} \sum_{j=1}^{n} w_{i j} r_{i j}$

Decision Support System In Determining Outstanding Teachers in Tutoring Institution Uses The Simple Additive Weighting Method (Ning Rahayu Lestari) 
Keterangan :

$\mathrm{Vi}=$ Nilai prefensi

$w j=$ Bobot yang telah ditentukan

rij $=$ Normalisasi matriks

Nilai Vi yang lebih besar mengindikasikan bahwa alternatif $A$ i lebih terpilih

\section{B. Pengujian}

Dalam tahap pengujian dibutuhkan data yang diperoleh dari bimbel. Data tersebut berupa data angket yang telah diisi oleh siswa bimbel dunia sausan tersebut. Untuk menganalisa dari data angket tersebut harus melakukan langkah-langkah sebagai berikut :

1. Angket yang telah diisi responden, diperiksa kelengkapan jawabannya, kemudian disusun sesuai koderesponden.

2. Mengkuantitatifkan jawaban setiap pertanyaan dengan memberi skor sesuai bobot yang telah ditentukansebelumnya.

3. Membuat tabulasi data.

Menghitung prosentase tiap sub variable dengan rumus :

Keterangan rumus :

$$
\%=\frac{N}{n} \times 100 \%
$$

$\%=$ Presentase sub variable

$\mathrm{n}=$ Jumlah skor tiap variable

$\mathrm{N}$ = Jumlah skor maksimum

Berdasarkan perhitungan di atas, maka range persentase dan kriteria

\section{Hasil dan Analisa}

Dalam bagian ini akan disimulasikan perhitungan Simple Additive Weighting untuk menentukaan pengajar yang berprestasi pada bimbel Dunia Sausan Kudus.

\subsection{Data yang Digunakan}

Data yang digunakan pada penelitian ini adalah menggunakan data penilaian pengajar yang berprestasi dengan mengisi nilai yang telah ditentukan pada kriteria.

Table 1. Menentukan pengajar berprestasi

\begin{tabular}{lccccc}
\hline & \multicolumn{5}{c}{ KRITERIA } \\
\hline ALTERNATIF & K1 & & K2 & K3 & K4 \\
\hline Bu Musda & 90 & 80 & 90 & 80 \\
Bu Riya & 70 & 80 & 60 & 60 \\
Bu Erni & 20 & 30 & 30 & 20 \\
Bu Afifah & 60 & 30 & 40 & 20 \\
Bu Reza & 10 & 10 & 40 & 20 \\
Bu April & 20 & 45 & 30 & 50 \\
Bu Diva & 50 & 40 & 50 & 60 \\
Bu Sofi & 70 & 70 & 30 & 50 \\
Bu Widia & 20 & 10 & 20 & 40 \\
\hline
\end{tabular}

TRANSFORMATIKA Vol. 17, No.01, July $2019: 88-96$ 


\subsection{Perhitungan Simple Additive Weighting}

Berdasarkan langkah-langkah dalam pemecahan masalah dengan metode Simple Additive Weighting yang telah dijelaskan sebelumnya, pada bagian ini akan dibahas tentang proses perhitungannya. Berikut adalah langkah penyelesaian metode SAW :

1) Menentukan kriteria-kriteria yang akan dijadikan acuan dalam pengambilan keputusan.

Table 2. Nilai bobot kriteria

\begin{tabular}{ccc}
\hline No. & Kriteria & Bobot \\
\hline 1. & Tanggung Jawab & 5 \\
2. & Persiapan Materi & 4 \\
3. & Kedisisplinan & 4 \\
4. & Menghasilkan Siswa Berprestasi & 5 \\
\hline
\end{tabular}

2) Menentukan bobot nilai subkriteria.

Table 3. Bobot nilai subkriteria

\begin{tabular}{rlc}
\hline \multicolumn{3}{c}{ NILAI KRITERIA } \\
\hline 1 & SANGAT BAIK & $76-100$ \\
0,5 & BAIK & $51-75$ \\
0 & CUKUP & $0-50$ \\
\hline
\end{tabular}

3) Menentukan rating kecocokan setiap alternatif pada setiap kriteria.

Table 4. Menentukan nilai pengajar berprestasi

\begin{tabular}{|c|c|c|c|c|c|c|}
\hline & \multicolumn{6}{|c|}{ KRITERIA } \\
\hline ALTERNATIF & K1 & $\mathrm{K} 2$ & $\mathrm{~K} 3$ & & K4 & \\
\hline Bu Musda & 90 & 80 & & 90 & & 80 \\
\hline Bu Riya & 70 & 80 & & 60 & & 60 \\
\hline Bu Erni & 20 & 30 & & 30 & & 20 \\
\hline Bu Afifah & 60 & 30 & & 40 & & 20 \\
\hline Bu Reza & 10 & 10 & & 40 & & 20 \\
\hline Bu April & 20 & 45 & & 30 & & 50 \\
\hline Bu Diva & 50 & 40 & & 50 & & 60 \\
\hline Bu Sofi & 70 & 70 & & 30 & & 50 \\
\hline Bu Widia & 20 & 10 & & 20 & & 40 \\
\hline
\end{tabular}

4) Membuat matriks keputusan berdasarkan kriteria $(C l)$, dengan menghitung matriks kinerja ternormalisasi (rij) dari alternative Ai pada atribut $\mathrm{Cj}$ berdasarkan persamaan yang disesuaikan dengan jenis atribut. Atribut untuk menormalisasikan ada 2 yaitu benefit (keuntungan) dan cost (biaya). Apabila atribut berupa benefit maka nilai crips (Xij) dari setiap kolom atribut dibagi nilai crips terbesar.

Apabila atribut berupa cost maka nilai crips (Xij) dari setiap kolom atribut dibagi nilai crips terkecil. Berikut adalah cara menormalisasi : 


$$
\begin{aligned}
& r_{11}=\frac{90}{\max \{90 ; 70 ; 20 ; 60 ; 10 ; 20 ; 50 ; 70 ; 20\}}=\frac{90}{90}=1 \\
& r_{21}=\frac{70}{\max \{90 ; 70 ; 20 ; 60 ; 10 ; 20 ; 50 ; 70 ; 20\}}=\frac{70}{90}=0,8 \\
& r_{31}=\frac{20}{\max \{90 ; 70 ; 20 ; 60 ; 10 ; 20 ; 50 ; 70 ; 20\}}=\frac{20}{90}=0,2 \\
& r_{41}=\frac{60}{\max \{90 ; 70 ; 20 ; 60 ; 10 ; 20 ; 50 ; 70 ; 20\}}=\frac{60}{90}=0,67 \\
& r_{51}=\frac{10}{\max \{90 ; 70 ; 20 ; 60 ; 10 ; 20 ; 50 ; 70 ; 20\}}=\frac{10}{90}=0,11 \\
& r_{61}=\frac{20}{\max \{90 ; 70 ; 20 ; 60 ; 10 ; 20 ; 50 ; 70 ; 20\}}=\frac{20}{90}=0,22 \\
& r_{71}=\frac{50}{\max \{90 ; 70 ; 20 ; 60 ; 10 ; 20 ; 50 ; 70 ; 20\}}=\frac{50}{90}=0,56 \\
& r_{81}=\frac{70}{\max \{90 ; 70 ; 20 ; 60 ; 10 ; 20 ; 50 ; 70 ; 20\}}=\frac{70}{90}=0,78 \\
& r_{91}=\frac{20}{\max \{90 ; 70 ; 20 ; 60 ; 10 ; 20 ; 50 ; 70 ; 20\}}=\frac{20}{90}=0,22
\end{aligned}
$$

Table 5. Matriks Ternormalisasi

\begin{tabular}{lccccccc}
\hline \multicolumn{7}{c}{ LANGKAH MENGHITUNG NORMALISASI } \\
\hline $\mathrm{R} 11$ & 1 & $\mathrm{R} 12$ & 1 & $\mathrm{R} 13$ & 1 & $\mathrm{R} 14$ & 1 \\
$\mathrm{R} 21$ & 0,78 & $\mathrm{R} 22$ & 1 & $\mathrm{R} 23$ & 0,67 & $\mathrm{R} 24$ & 0,75 \\
$\mathrm{R} 31$ & 0,22 & $\mathrm{R} 32$ & 0,38 & $\mathrm{R} 33$ & 0,33 & $\mathrm{R} 34$ & 0,25 \\
$\mathrm{R} 41$ & 0,67 & $\mathrm{R} 42$ & 0,38 & $\mathrm{R} 43$ & 0,44 & $\mathrm{R} 44$ & 0,25 \\
$\mathrm{R} 51$ & 0,11 & $\mathrm{R} 52$ & 0,13 & $\mathrm{R} 53$ & 0,44 & $\mathrm{R} 54$ & 0,25 \\
$\mathrm{R} 61$ & 0,22 & $\mathrm{R} 62$ & 0,56 & $\mathrm{R} 63$ & 0,33 & $\mathrm{R} 64$ & 0,63 \\
$\mathrm{R} 71$ & 0,56 & $\mathrm{R} 72$ & 0,5 & $\mathrm{R} 73$ & 0,56 & $\mathrm{R} 74$ & 0,75 \\
$\mathrm{R} 81$ & 0,78 & $\mathrm{R} 82$ & 0,88 & $\mathrm{R} 83$ & 0,33 & $\mathrm{R} 84$ & 0,63 \\
$\mathrm{R} 91$ & 0,22 & $\mathrm{R} 92$ & 0,18 & $\mathrm{R} 93$ & 0,22 & $\mathrm{R} 94$ & 0,5 \\
\hline
\end{tabular}

5) Hasil akhir diperoleh dari proses perankingan yaitu penjumlahan dari perkalian matriksternormalisasi $R$ dengan vektor bobot sehingga diperoleh nilai terbesar yang dipilih sebagai alternatif terbaik.

$$
\begin{aligned}
& \text { V1 }=(1)(5)+(1)(4)+(1)(4)+(1)(5)=18 \\
& \text { V2 }=(0,78)(5)+(1)(4)+(0,67)(4)+(0,75)(5)=14,33 \\
& \text { V3 }=(0,22)(5)+(0,38)(4)+(0,33)(4)+(0,25)(5)=5,19 \\
& \text { V4 }=(0,67)(5)+(0,38)(4)+(0,44)(4)+(0,25)(5)=7,88 \\
& \text { V5 }=(0,11)(5)+(0,13)(4)+(0,44)(4)+(0,25)(5)=4,08 \\
& \text { V6 }=(0,22)(5)+(0,56)(4)+(0,33)(4)+(0,63)(5)=7,81 \\
& \text { V7 }=(0,56)(5)+(0,5)(4)+(0,56)(4)+(0,75)(5)=10,79 \\
& \text { V8 }=(0,87)(5)+(0,88)(4)+(0,33)(4)+(0,63)(5)=11,89
\end{aligned}
$$

TRANSFORMATIKA Vol. 17, No.01, July 2019: $88-96$ 
$\mathrm{V} 9=(0,22)(5)+(0,18)(4)+(0,22)(4)+(0,5)(5)=5,2$

Hasil perangkingan diperoleh V1 $=18, \mathrm{~V} 2=14,33, \mathrm{~V} 8=11,89$. Nilai terbesar adalah $\mathrm{V} 8$, dengan demikian alternatif $\mathrm{A} 8$ adalah alternatif yang terpilih sebagai alternatif terbaik.

\subsection{Implementasi Sistem}

Implementasi sistem adalah tahap dimana sistem yang dirancang pada tahap sebelumnya harus diterapkan, berupa perangkat lunak maupun perangkat keras yang digunakan. Aplikasi ini terdapat halaman utama. Pada saat membuka aplikasi ini, akan tampil halaman utama user.

\section{Halaman Bobot}

Pada halaman bobot ini admin bisa melakukan tambah nilai bobot, edit nilai bobot, hapus nilai bobot. Supaya admin bisa memberi nilai bobot pada setiap kriteria yang diinginkan.

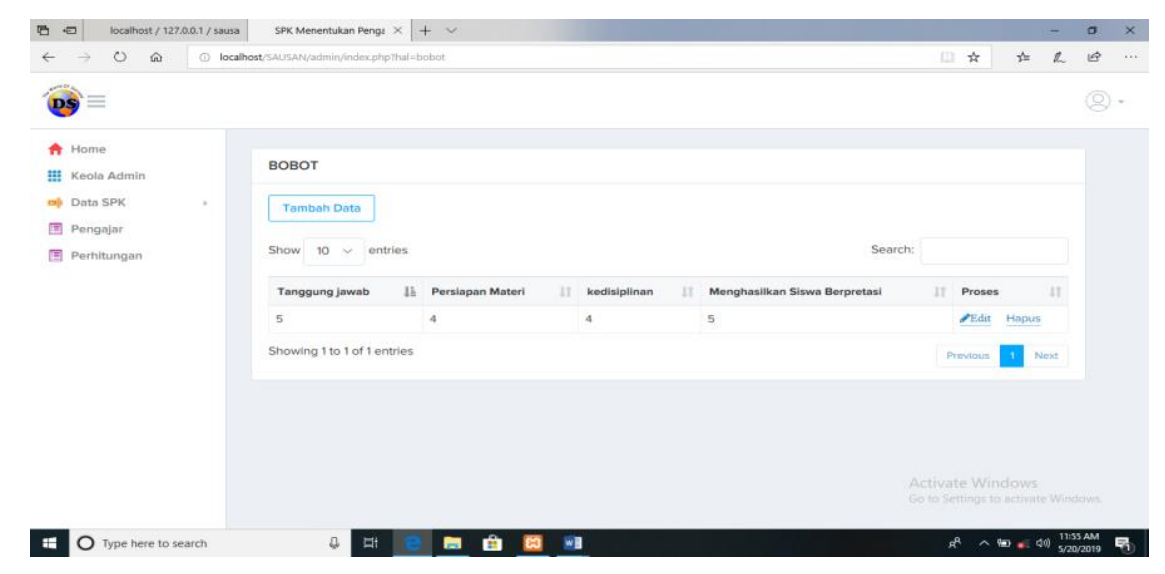

Gambar 2. Halaman bobot

\section{Halaman Alternatif}

Pada halaman alternatif ini admin bisa melakukan tambah data alternatif, edit data alternatif, hapus data alternatif. Supaya admin bisa memberi nilai alternatif pada setiap pengajar dengan kriteria yang diinginkan. 


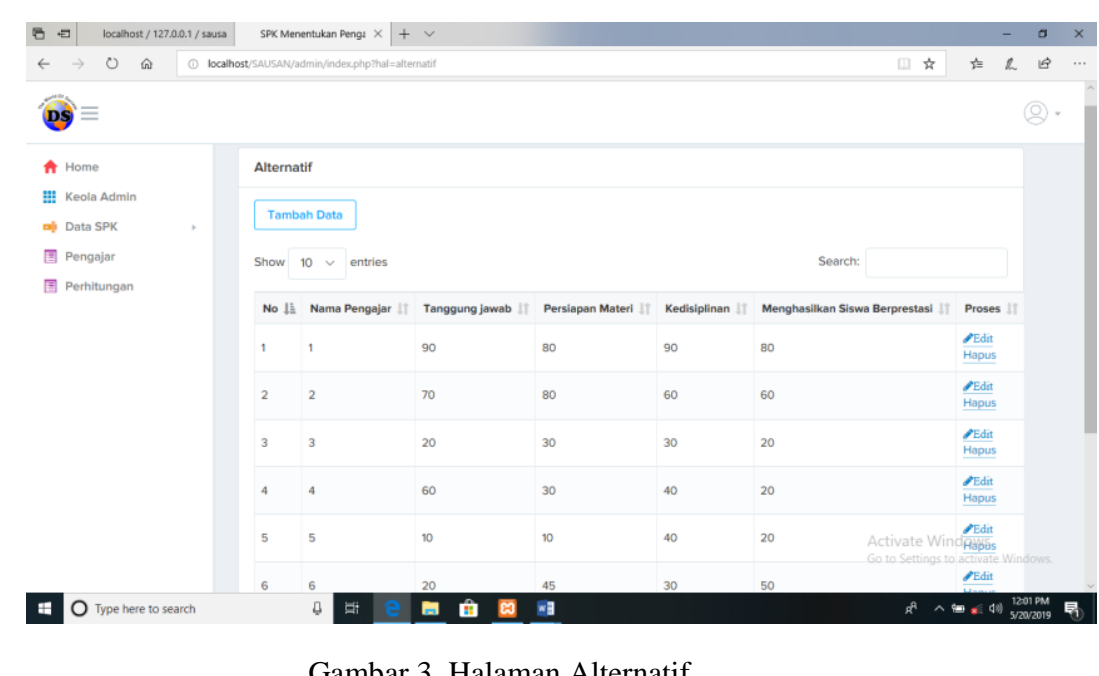

Gambar 3. Halaman Alternatif

\section{Halaman Perhitungan}

Pada halaman perhitungan admin bisa melihat hasil perhitungan yang menggunakan metode Simple Additive Weighting, pada gambar bisa terlihat hasil perhitungan matrik normalisasi dan dan perankingan. Di gambar menjelaskan bahwa pengajar yang bernama Bu Musda memiliki total point 340 dan perhitungan Simple Additive mendapat nilai 1 yang menjadi juara pertama.

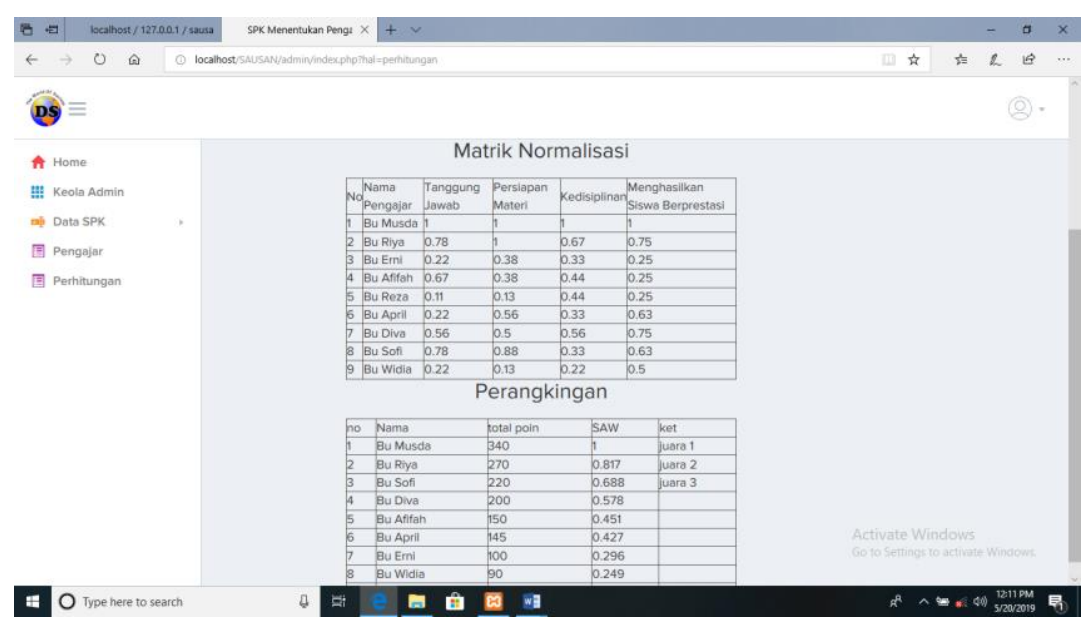

Gambar 4. Halaman perhitungan

\section{Kesimpulan}

Dari Analisa dan pembahan yang telah dilakukan maka dapat ditarik sebuah kesimpulan yaitu proses menentukan pengajar yang berprestasi dengan kriteria dapat diselesaikan sebuah sistem pada computer yang mampu berinteraksi dengan mangambil suatu keputusan, sistem pendukung keputusan (SPK) menentukan pengajar yang berprestasi dalam perhitungan menggunkan metode Simpe additive weighting (SAW), dalam menentukan pengajar yang berprestasi yang tepat dapat meminimalkan resiko yang terjadi.

\section{References}

[1] Ian Septiana, Mohammad Irfan, Aldy Rialdy Atmadja, Beki Subaeki. "Sistem Pendukung Keputusan Penentuann Dosen Penguji dan Pembimbing Tugas Akhir Menggunakan Fuzzy Multiple Attribute Decision Making dengan Simple Additive Weighting". JOIN, vol. 1, pp. 4350, 2016.

TRANSFORMATIKA Vol. 17, No.01, July 2019: $88-96$ 
[2] Rotua Sihombing Hutasoit, Agus Perdana Windarto, Dedy Hartama, Solikhun. "Sistem Pendukung Keputusan Pemilihan Guru Terbaik Pada SMK Maria Goretti Pematangsiantar Menggunakan Metode Simple Additive Weighting (SAW)". J. Riset Sistem Informasi \& Teknik informatika, vol. 1, pp. 56-63,2016.

[3] Surya Candra. "Sistem Pendukung Keputusan Rekomendasi Penerimaan Beasiswa Menggunakan Fuzzy Multi Attribut Decision Making (FMADM) dan Simple Additive Weighting (SAW)". J.Rekayasa Elektrika, vol. 11, pp. 146-156,2015.

[4] Teuku Mufizar. "Sistem Pendukung Keputusan Pemilihan Dosen Berprestasi Di STMIK Tasikmalaya Menggunakan Metode Simple Additive Weighting (SAW)". J.CSRID Journal, vol. 7, pp. 155-167,2015.

[5] Sri Eniyati. "Sistem Pendukung Keputusan Pengambilan Keputusan untuk Penerimaan Beasiswa dengan Metode SAW (Simple Additive Weighting)". J.Teknologi Informasi DINAMIK, vol. 16, pp. 171-177, 2011.

[6] Dwi Citra Hartini, Endang Lestari Ruskan, Ali Ibrahim. "Sistem Pendukung Keputusan Pemilihan Hotel Di Kota Palembang Dengan Metode Simple Additive Weighting (SAW)". J.Sistem Informasi, vol. 5, pp. 546-565, 2013.

[7] Nandang Hermanto. "Sistem Pendukung Keputusan Menggunakan Metode Simple Addtive Weighting (SAW) Untuk Menentukan Jurusan Pada SMK Bakti Purwokerto". Seminar Nasional Teknologi Informasi \& Komunikasi, pp. 52-62, 2012.

[8] Fajar Nugraha, Bayu Surarso, Beta Noranita. "Sistem Pendukung Keputusan Evaluasi Pemilihan Pemenang Pengadaan Aset dengan Metode Simple Additive Weighting (SAW)". J.Sistem Informasi Bisnis. pp. 67-72, 2012.

[9] Yadi Utama. "Sistem Pendukung Keputusan Untuk Menentukan Penanganan Perbaikan Jalan menggunakan Metode Saw Berbasis Mobile Wes". J.Sistem Informasi , vol. 5, pp. 566$579,2013$.

[10] Yoga Radhitya, Fitro Nur Hakim, Achmad Solechan. "Rancang Bangun Sistem Pendukung Keputusan Penentuan Penerimaan Beasiswa Dengan Metode S 